\title{
Lightning Birds: An Aeroecology of the Airwaves
}

\section{Curatorial Essay}

Radio has long been understood in relation to the sky. Newspapers announced the earliest demonstrations of "wireless telegraphy" with headlines like "Messages in the Air" and "Out of the Clouds." We speak of radio existing in the "airwaves," and commercial imagery like the RKO "Radio Pictures" logo depicts lightning bolts radiating over the Earth. With its infrastructure of tall transmission towers and messages carried by electromagnetic waves passing through the atmosphere, radio can be understood as what John Durham Peters calls a "sky medium," with other examples being flags, beacons, spotlights, fireworks, and towers. ${ }^{2}$

We're used to thinking about radiophonic communication existing in the sky, but it's less frequently acknowledged that humans share that celestial space with other creatures; most notably, with birds. Birds rely upon the "aerosphere"- the part of the troposphere closest to the Earth's surface - as a habitat, a medium of movement, and a source of food. ${ }^{3}$ Some bird species spend such prolonged periods in the airspace, eating, mating, and even sleeping there, that they are essentially amphibious creatures, leading a double life between sky and land. For birds that make long migratory flights, the aerosphere is a landscape imbued with value and significance, as they orient to the sun and the stars, gauge the winds, and monitor the changing seasons. ${ }^{4}$

As our technologies move into the sky, they make contact with this aerospheric habitat. In the case of radio, transmission towers become obstacles in birds' flight paths; radar systems emit signals that reveal the large-scale movements of birds; parabolic microphones directed at the sky eavesdrop on avian flight calls; and miniature radio transmitters accompany birds on their global travels. Lightning Birds explores the contact zone demarcated by these points of intersection, riding the crosswinds of bird migration and radio history to undertake an aeroecology of the airwaves.

Lightning Birds tells a new story about radio. Most histories consider radio as a platform for popular entertainment or political communication, but Lightning Birds explores the medium's use as a tool for generating knowledge about bird migration. I understand radio to be an assemblage of technological devices, along with the protocols for using them. Some of the key 
components in the radio assemblage are transmission stations, towers, microphones, radio waves, recording devices, and tube or transistor amplifiers. ${ }^{5}$ Lightning Birds takes apart the radio assemblage to show how its component parts have played an important role in the domain of ornithology, revealing radio's double life as both a cultural practice and a scientific technique. ${ }^{6}$ Retelling radio history from the perspective of ornithology — more specifically, the study of bird migration - has a number of productive results: understudied practices like radar and radio telemetry are brought into the narrative; new historical precursors to radio are discovered; attention shifts from familiar subjects like media corporations and national broadcasting networks to scientific communities and citizen science initiatives; and the materiality of the medium is scrutinized from a fresh perspective. ${ }^{7}$

The approach to radio history heard on Lightning Birds is meant to orient the study of radio toward the growing body of environmentally minded media scholarship. ${ }^{8}$ One inspiration for the project was a question posed by Anna Tsing and her collaborators. They asked: "How can we repurpose the tools of modernity against the terrors of Progress to make visible the other worlds it has ignored or damaged?"9 Radio has been a quintessential tool of modernity, and Lightning Birds repurposes its history so that another world becomes audible - the world of the avian aerosphere.

In addition to radio history, Lightning Birds is in conversation with literature that explores the intersection of media and the environment; more specifically, with scholarship that investigates the lifeways of animals, and that takes an infrastructural, material, or "geological" approach to media technology. With regard to the former, Thom Van Dooren describes how avian "flight ways," by which he means nonhuman "ways of life" that are "shared, produced, and nurtured in the world through the work of successive generations," have become entangled with humans. ${ }^{10}$ Bird's seasonal migratory journeys are a vivid example of avian flight ways, and Lightning Birds explores how human technologies like radio have become part of a "web of interactions" with the long evolutionary history of migration. ${ }^{11}$ In some cases, radio's avian entanglements have resulted in deadly obstacles for birds, but in others they have provided opportunities to better understand and protect their flight ways, serving as a means to foster what Alexandra Hui calls "imagined ecologies."12

When radio history is tuned to the migratory flight ways of birds, we get a powerful reminder that the "environment" is not a static background to human travel and long-distance 
communication. ${ }^{13}$ Indeed, birds' seasonal flights around the globe have been called "the most spectacular long-distance migrations of any organism on the planet," enacting "the biological integration of seemingly disparate ecosystems around the globe." ${ }^{14}$ In Lightning Birds, radio-an iconic technology of virtual travel - is aligned with avian travel, and so contributes to recent scholarly work on mobility. ${ }^{15}$

One of the lessons of mobility studies is that for some things to be moving, other things need to be standing still. That is, mobility is facilitated by local and material "immobilities": trains run on tracks; airplanes need airports; radio and television broadcasts require stations, cable systems, or satellites; and digital communication relies upon fiber-optic cables. ${ }^{16}$ That insight applies to a radio history reconfigured around bird migration, because such an approach requires that we consider the medium's immobile material infrastructure as well as its mobile airwaves. Inspired by the work of scholars like Nicole Starosielski, Lisa Parks, and Brian Larkin, Lightning Birds enacts an infrastructural "network archaeology" of the radio assemblage as it intersects with the aerospheric environment. ${ }^{17}$ This is most prominent in episode two, which describes how radio towers became sites of ornithological research. I argue that citizen scientists who studied the birds killed at communication towers were amateur media scholars, undertaking what Lisa Parks calls a "node-centric approach" to media studies, which involves exploring "the material conditions that support and surround" a single media infrastructure site. ${ }^{18}$

Lightning Birds also takes up Jussi Parikka's call for a "geology of media." Parikka urges scholars to find "strains of media materialism outside the usual definition of media." "Instead of radio," he writes, "I prefer to think what components and materials enable such technologies."19 Lightning Birds is similarly interested in the materials that enable radio in both its popular and ornithological modes. In particular, aluminum has provided much of the material scaffolding for the aerospheric contact zone I explore: the lightweight metal leg bands used to track migratory birds; the airplanes and skyscrapers that have moved into avian flight paths; and many aspects of the radio assemblage, from its electronic components and portable casings, to the transcription discs that have preserved its ephemeral broadcasts. ${ }^{20}$

Aluminum became synonymous with streamlined speed and lightweight strength, but it is the result of an earthbound, dirty, and energy-intensive production process. In fact, aluminum smelting has been called "one of the most energy-intensive production processes on earth."21 Radio's invisible airwaves therefore relied upon a carbon-intensive industrial process that has 
had very real consequences for the planet's climate and ecosystems. The "geology of radio" heard on Lightning Birds provides a complement to current scholarship that reveals the hidden energy costs and lingering toxic materiality of Hollywood cinema and the supposedly immaterial forms of digital, "cloud-based" media. ${ }^{22}$

Lightning Birds draws upon scholarship from media studies, environmental studies, sound studies, and ornithology, but my goals are not solely intellectual. There is an urgent need to understand and appreciate the avian aerosphere, given that 13 percent of all bird species, or one in eight, are threatened with extinction. ${ }^{23}$ A recent study in the journal Science found a net loss of close to three billion birds since 1970, or 29 percent of the total bird abundance, signaling "an urgent need" to avert future collapse and "associated loss of ecosystem integrity, function and services." 24 It is in this context that I want to tune the frequencies of radio history to the aerosphere, since the more we know about birds and their use of the sky, the more we can acknowledge and minimize our destructive actions. ${ }^{25}$ Human activities threaten migratory birds through the fragmentation and loss of habitat, the disruptions of climate change, noise and light pollution, and the various obstacles we erect in their paths. ${ }^{26}$

Such threats to migratory populations are troubling in and of themselves, but there are even larger stakes, given that birds have been called "sensitive environmental indicators, often heralding key changes in environmental processes or ecosystem health." 27 Birds have long functioned for humans as a form of "logistical media" in the sense that they orient us in time and space. For example, the nature writer John Burroughs described how his sense of the seasons was shaped by the arrival of migrating birds. It was sure to be a March morning he wrote when you first heard a bluebird, and the call of the blackbird was "the voice of April." 28 The claim that birds are "sensitive environmental indicators" shows that they now serve as logistical media in a new sense: as barometers for gauging the environmental health of the planet.

The goal of ecocriticism is not only to make people understand a topic like bird migration, but to care about it. To do that, critics need to consider all the channels of communication and affective registers at their disposal. Lightning Birds is a study of the sonic medium of radio, and it has been conceived as a work of audio. In that regard, it is an example of audiography: criticism that takes audio form and uses sound as an essential component in the making of an argument. Lightning Birds builds upon my first audiographic publication, ESC: Sonic Adventure in the Anthropocene (University of Michigan Press, 2019). ${ }^{29}$ As with ESC, 
Lightning Birds consists of a series of audio chapters/episodes that are available for streaming or download at no cost at the University of Michigan Press website. In addition to the audio files that form the heart of the project, the website also includes this curatorial essay, a bibliography for each episode, and an online audio transcription that can be used for academic citation.

Audiographic projects like Lightning Birds have the potential to communicate scholarship to a wide range of audiences, both within and beyond the academy. The multidisciplinary scope and podcast-style, episodic structure of Lightning Birds are intended to make the project accessible to a number of potential listeners, including historians, media scholars, sound artists, environmental activists, ornithologists, and bird enthusiasts. Audiography broadens the sensory range of scholarly writing, and I am interested in how sound might facilitate the process of "learning to be affected" by the avian world. ${ }^{30}$ It is important for ecocritical communication to mobilize a range of intellectual, emotional, and sensual appeals because barriers to pro-environmental behavior involve a person's values, attitudes, and levels of emotional involvement as much as the lack of information. ${ }^{31}$

To that end, I supplement my interviews and spoken analysis with sonic elements that take advantage of audio's ability to move into more emotional or poetic registers: excerpts from audio dramas, works of sound art, and tracks by the renowned electronic musicians Dominik Eulberg and Four Tet. Audio is also mobilized in Lightning Birds to situate listeners in an "avian audioposition," that is, to allow them to hear from the perspective of birds. I refer to uses of the radio assemblage that present an avian audioposition as "aerospheric radio." My hope is that this type of audio might function to expand our sympathies beyond the human, and help us to grasp the lived experience of the aerosphere as habitat. ${ }^{32}$

There are two sonic elements that recur across all five episodes of Lightning Birds, and that are intended to make the project resonate on poetic and narrative registers: spoken excerpts from Velimir Khlebnikov's poetic essay, “The Radio of the Future” (1921), and audio clips from adaptations of Paul Gallico's modern fairy tale, "The Snow Goose” (1940). My title comes from a line in Khlebnikov's essay, where he describes radio signals as a "stream of lightning birds." 33 That image portrays, in miniature, the contact zone between radio history and bird migration that I explore in the project. Quotes from "The Radio of the Future" serve as epigraphs at the start of each episode. Gallico's "The Snow Goose" is the tale of a migrant bird blown off course, and it serves as a kind of narrative "carrier bag" across the episodes; that is, clips from a number of 
media adaptations of the story become stopover sites where the listener is given the chance to process the historical and scientific information that they have encountered over the course of the project's five episodes. ${ }^{34}$ Ursula Heise argues that environmental science gains sociocultural traction to the extent that it becomes "part of the stories that human communities tell about themselves." 35 My goal is for "The Snow Goose" to serve as a human story that helps to orient listeners to both the science and wonder of bird migration.

Thus far, I have described the overarching goals and primary scholarly interlocutors for Lightning Birds, as well as the audiographic form of the project. Lightning Birds is a work of multimodal publishing with audio at its core, and you might think of this essay as the "liner notes" for the five episodes hosted at the University of Michigan website. In the balance of this curatorial essay, it only remains to sketch a brief overview of each episode.

\section{Episode One: Station}

The first episode introduces the project, and then turns to the practice of bird banding, which has been called "the oldest, and by far the most important, means of studying bird migration." banding involves placing a marked ring on a bird's leg, and by the 1920s, a national network of volunteer banding stations had been established across the United States. In my first gesture toward a new kind of radio history, I describe a series of parallels between the bird banding network and a network of amateur radio stations that was coalescing at the same time. Radio operators and bird banders were both amateur hobbyists and tinkerers, and shared an interest in linking their home stations in a network of long-distance communication and informationsharing. Where radio hobbyists engaged in "exploratory listening," striving to listen to as many distant stations as they could, bird banders sent messages in the form of numbered leg bands attached to migratory birds from their home stations to be received and recorded at locations around the globe. ${ }^{37}$

Both of these networks enacted a modern social dynamic that Raymond Williams calls "mobile privatization," which negotiates paradoxical tendencies toward increased mobility and the privatization of the family home. For Williams, broadcasting functioned to resolve those "contradictory pressures" by satisfying "the wish to go out and see new places" while remaining 
in the privacy of the home. ${ }^{38}$ The network of amateur radio stations was the first embodiment of mobile privatization in the realm of radio communication, and bird banders manifested something similar in the field of ornithology, tracking the global movements of migratory birds without leaving the privacy of the home laboratory. ${ }^{39}$

Episode one introduces the topic of aluminum, which is the focus of the project's material history of radio. Aluminum provided the lightweight but durable leg bands needed for bird banding, and it was a key component in radio sets. Aluminum was also essential to the growth of aviation, accelerating the movement of human travel, commerce, and communication into the aerosphere. ${ }^{40}$ The shared use of aluminum is a material articulation between bird banding and radio, and thinking them together as sky media leads to the discovery of surprising precursors to radio, such as singing kites and pigeon whistles. ${ }^{41}$

Each episode of Lightning Birds covers both a chapter of radio history and a set of scientific discoveries about bird migration that have resulted from the mobilization of a component in the radio assemblage. Episode one delineates some of the knowledge generated by the network of bird banding stations, including evidence of the global scope of migration. Banding helped to establish that the flight paths of migratory birds do not recognize national borders, and that international cooperation was needed to protect migratory species. Bird banding data showed the extent to which avian migration was a global phenomenon, and thus helped to spur pioneering legislation like the Migratory Bird Treaty Act of 1918. Now, a century later, anthropogenic climate change is creating a new threat to that already precarious process. The episode concludes with a discussion of "mismatch," which is when the seasonal activities of plants and animals change as the result of climate change, causing a troubling disconnect between the timing of birds' migratory journeys and the seasonal availability of food. ${ }^{42}$

\section{Episode Two: Tower}

Towers, writes John Durham Peters, are sky media that "mediate between heaven and earth" by reaching up into the aerosphere to extend communication and gain social leverage on the Earth below. ${ }^{43}$ Episode two concerns instances when towers have come into contact with the flight ways of birds. I begin with lighthouses, sites where the combination of height, illumination, and 
coastal location proved fatal for many migratory birds. ${ }^{44}$ Lighthouses were the first place where people noticed the phenomenon known as "towerkill," when birds collide with tall structures. As a result, lighthouses became an important site of research on bird migration, demonstrating how infrastructure can establish a contact zone between human and nonhuman environments.

Lighthouses are not usually part of the history of broadcasting, but they enter the story when radio is framed as a sky medium. Episode two presents another novel historical precedent to radio in the form of premodern techniques of sonic "broadcasting" from tall towers, as in the case of church bells and the practice of "tower music." 45 The entanglement of towers and bird migration continued into the era of electronic media when tall, illuminated radio towers moved into the aerosphere. Lighthouses had been confined to the coast, but radio towers were constructed across the country, and by the end of the 1930s communication towers had transformed the entire continent into what Lisa Parks calls a "signal territory": a landscape blanketed with "broadcast facilities, including stations, towers, antennas, and microwave links." ${ }^{46}$ As had been the case with lighthouses, communication towers not only killed migratory birds, but became a source of data about them, and I discuss citizen science initiatives at radio and television towers that began in the 1950s. As mentioned above, such efforts can be understood as both amateur ornithology and amateur media studies, since they enacted a "nodecentric approach" that explored "the material conditions that support and surround a single broadcast infrastructure site. ${ }^{47}$

Radio and television towers were part of a new American skyline that was made possible, in part, by aluminum. Communication towers were generally made of steel, but they were rising at the same time that aluminum was helping to define a modernist style of architecture that featured streamlined forms and an expanded role for glass. According to Mimi Sheller, designs for skyscrapers like the Empire State Building (1935) "would not have been possible without aluminum." ${ }^{48}$ The symbolic home of radio and the modern electronic soundscape was the iconic Radio City Music Hall (1932), where one could find aluminum used as exterior trim, aluminum foil wallpaper, and in the form of several sculptures made entirely of aluminum. A "geology of media" approach connects radio - via aluminum — to a broader pattern whereby modern architectural forms were moving further into the aerosphere.

The first episode of Lightning Birds describes how lightweight aluminum was a crucial component in aviation. The aviation theme continues in episode two, where we learn that, in 
1937, the Federal Communication Commission (FCC) required lights to be placed on radio towers to avoid airplane collisions. ${ }^{49}$ Illuminated towers kept the airplanes away, but, like lighthouses before them, they created a hazard for migratory birds, especially on overcast nights. Towerkill continues to be a serious problem, but there have been some important regulatory success stories and citizen initiatives concerning the issue in recent years. In episode two, the scientist Joelle Gehring speaks about her research into bird collisions, which helped to inspire recent changes in tower lighting policy, with important implications for migratory birds. ${ }^{50} \mathrm{We}$ also hear from Annette Prince, the director of the Chicago Bird Collision Monitors, who describes the work of her volunteer organization and ongoing efforts to minimize the impact of urban design for migratory birds.

\section{Episode Three: Waves}

Episode three begins by describing the development of several systems of logistical radio in the 1920 s and '30s, the most significant of which was radar, which scans the sky in order to collect information about objects at a distance. ${ }^{51}$ The development of radar was spurred by the need to locate aluminum-clad aircraft during World War II, but confusion arose when technicians began to notice mysterious, unidentified echoes on their display screens, which they called "angels." It was eventually established that most radar angels were birds, and after the war, birds became the object of intentional and systematic study with radar. ${ }^{52}$

The field of radar ornithology stands as a dramatic example of the radio assemblage being applied to the study of birds, and it has yielded many discoveries about avian migration. One of the insights drawn from radar was that birds flew along straight paths even when clouds covered the sky, which suggested that birds had other means of orientation besides visual cues. ${ }^{53}$ In fact, some experiments with radar seemed to suggest that avian navigation might involve the perception of electromagnetic fields. In the 1960s, experiments confirmed that some birds do orient using the Earth's magnetic field. ${ }^{54}$ The contact zone encompassing the airwaves and the aerosphere thus articulates a perceptual inclination shared between birds and our logistical media, with migrating birds practicing a kind of "natural radio" to the extent that they navigate using the magnetic fields that encompass the planet. $^{55}$ 
Episode three features an interview with Sidney Gauthreaux, a leader in radar ornithology since the 1970s. Gauthreaux analyzed radar images from the 1960s to 1980s and found that "the number of flights of migratory birds had dropped by nearly 50 percent."56 Gauthreaux's research spurred the development of the international conservation initiative "Partners in Flight," a network of more than 150 partner organizations with the goal of halting and reversing declines in bird population. ${ }^{57}$

\section{Episode Four: Microphone}

Episode four examines the use of sound technologies to study the flight calls of migratory birds. Unlike the more complex and melodious songs sung by birds, flight calls are "cryptic little buzzes and whistles" that are thought to aid birds in flocking and orientation. ${ }^{58}$ Flight calls were first used as a method for studying nocturnal migration at the end of the nineteenth century, and that method was given a boost in the 1950s with the new availability of recording devices that utilized magnetic tape technology.

After episodes dedicated to stations, towers, and radio waves, it is microphones and recording devices that are the featured components of the radio assemblage in episode four. Sound recording became fully integrated into the practice of radio broadcasting during the 1940s and 1950s, but, before that, aluminum transcription discs were the material archive for much of what we now know as "old time radio." Sound recording also became an important tool in studying the vocal behavior of birds. ${ }^{59}$ The Cornell Lab of Ornithology was a center for that work, developing techniques for recording with parabolic microphones, and releasing a series of popular phonograph records of birdsong. ${ }^{60}$ Tape recording was also used in research on migratory flight calls, and this episode details pathbreaking experiments that directed a parabolic microphone toward the sky to record flight calls onto a custom-made reel-to-reel tape recorder. I trace this line of research into the era of digital sound-recognition and analysis software, as well as do-it-yourself rooftop recording kits that transform the lived environment into a network of listening devices directed at migratory birds. ${ }^{61}$

The episode concludes with the assertion that birds are listening back, turning their ears downward, toward the landscape. Many migratory birds hear sound at considerably lower 
frequencies than humans, and the scientist Jonathan Hagstrum explains how sounds made by low-frequency "infrasonic landmarks" such as ocean waves and steep-sided mountains may serve as "acoustic beacons" that orient birds on their long-distance journeys. ${ }^{62}$ Avian infrasonic perception is offered as another way in which a sonic perspective might help us to better understand avian lifeways, and to aid in that project, we hear experimental recordings made from a hot air balloon, allowing the listener to inhabit the aerospheric audioposition of migratory birds.

Episode Five: Amplifier

The consumer radio sets of the 1920s were amplified by vacuum tubes, but a new generation of "solid state" components was developed in the 1940s. Solid state technology was developed for radar, which required a degree of sensitivity to extremely high-frequency electromagnetic waves that tubes could not provide. Tubes were also large and fragile, which meant that tube-era radios were not very portable. ${ }^{63}$ Research into solid state components continued after the war, and in 1947 Bell Laboratories unveiled its new transistor technology. Aluminum, as well as plastic, allowed for the miniaturization and portability of consumer electronics, including the first "shirtpocket" radios made with transistors that hit the market in the 1950s. ${ }^{64}$ The final episode of Lightning Birds considers the ways in which transistors reshaped the radio assemblage, both in terms of the iconic portable radios of the 1950 s and ' 60 s and the small radio telemetry devices that ushered in a new era of studying bird migration. ${ }^{65}$

Returning to themes introduced in the first episode, I argue that transistor technology marked a shift from "mobile privatization" to a "privatized mobility" in which previously domestic experiences could be taken on the move. ${ }^{66}$ Tiny, transistorized transmitters facilitated a shift from the mobile privatization of bird banding, in which recovered aluminum leg bands brought information about the global movements of birds to a home station, to the privatized mobility of radio telemetry, in which radio equipment, and the researchers themselves, were taken out of the lab and put into motion. Telemetry revealed the patterns of bird migration with a new level of detail, and it continues to be an active area of research, from satellite tracking devices, to light-level geolocators, to animal tracking apps downloadable to a smartphone. ${ }^{67}$ 
Short excerpts from an interview with engineer and scientist William Cochran are heard in episodes two and four, but Cochran takes center stage here. This is fitting, given his status as a pioneer of wildlife radio telemetry. Continuing the exploration of an avian audioposition, we listen to sound recordings made from transmitters attached to birds in flight, and consider the aesthetics of such recordings in relation to sound artist Antoine Bertin's "Twelve Hours in the Life of a Fox." Telemetry is not without its critics, some of whom have argued that the practice has the capacity to "spectralise" wild birds, rendering them as "ghost-like digital signals." 68 Bertin's work suggests another way to hear those sonic signals, one that is more aligned with Alexander Pschera's notion of the "Animal Internet," which he claims "has the potential to revive the human-animal relationship" by giving specific animals an identity and a backstory. ${ }^{69}$

Like Bertin, Pschera thinks that telemetry is establishing "a new notion of beauty" in representations of the nonhuman world, moving away from "the high-definition, super slowmotion style" of nature documentaries, to an "unfocused, pixelated, and blurry" style that presents "seemingly banal images" of animals in "the nearby woods or meadow." "70 it in this spirit that we listen to recordings made by William Cochran using tiny microphones attached to migratory birds. Like the balloon recordings from the last episode, these are sounds made at that crosswinds of radio art and ornithological research, and that can open our ears to an avian audioposition. $^{71}$

Lightning Birds concludes with a discussion of the final scenes of Paul Gallico's "The Snow Goose." Gallico's tale concerns a bird that goes off course of its migratory script to form a multispecies family with humans, and so serves as a figure for kinship and multispecies collaboration in precarious times. ${ }^{72}$ To illustrate how "The Snow Goose" extends the emotional economy of a traditional love story to include animals and ecosystems, we listen to excerpts from a musical adaptation made in 1975 by the progressive rock band Camel.

The ending of "The Snow Goose" has a wistful, downbeat, and elegiac tone. In Lightning Birds, however, I want to avoid becoming oversaturated with that affective register and, to borrow the words of Ursula Heise, find a way to "move beyond mourning, melancholia, and nostalgia to a more affirmative vision of our biological future." ${ }^{, 73}$ With that goal in mind, we turn for balance to our other literary beacon, Velimir Khlebnikov's "The Radio of the Future," which is a Futurist manifesto buzzing with utopian optimism about radio technology. Given radio's role in the "terrors of Progress" that have ushered us into the Anthropocene epoch, this kind of 
technological utopianism must also be tempered. With "The Snow Goose" and "The Radio of the Future," we find ourselves caught between what Heise characterizes as a narrative of "the decline of nature" and "progress boosterism." 74

In pursuit of equilibrium between elegy and ode to progress, I turn to the Science report cited above, which states that, despite the general downward trend in bird populations, waterfowl like snow geese are among the species whose numbers are growing. That growth is due, in part, to successful conservation efforts, such as the creation of wildlife refuges and limits to hunting. ${ }^{75}$ The growing numbers of snow geese have created their own ecological problems, but nevertheless the species might stand as a much-needed emblem of resilience, as well as a reminder that conservation efforts can work when backed by political will and strategic social alliances. Lightning Birds ends then, somewhere between the "utter desolation" at the end of "The Snow Goose" and the utopian modernism of "Radio of the Future." Perhaps it is in this hybrid narrative terrain, between fairy tale and Futurist manifesto, between the science and poetry of airwaves and aerosphere, that we can discover a new role for radio, one in which, to paraphrase Khlebnikov, a flock of news is transmitted that comes from the life of the planet.

1 "Messages in the Air," Washington Post, July 3, 1898, 23. "Out of the Clouds," Los Angeles Times, October 31, 1899, 5.

${ }^{2}$ John Durham Peters, The Marvelous Clouds (Chicago: University of Chicago Press, 2015).

${ }^{3}$ Thomas H. Kunz, Sidney A. Gauthreaux Jr., Nickolay I. Hristov, Jason W. Horn, Gareth Jones, Elisabeth K. V. Kalko, et al., "Aeroecology: Probing and Modeling the Aerosphere," Integrative and Comparative Biology 48, no. 1 (2008): 1; Philip B. Chilson, Winifred F. Frick, Jeffrey F. Kelly, Felix Liechti, eds., Aeroecology (Cham, Switzerland: Springer, 2017); Robert H. Diel, “The Airspace Is Habitat,” Trends in Ecology \& Evolution 27, no. 7 (July 2013).

${ }^{4}$ Thom Van Dooren, Flight Ways (New York: Columbia University Press, 2014), 72.

${ }^{5}$ On assemblages, see Bruno Latour, “On Actor-Network Theory: A Few Clarifications,” Soziale Welt 47, no. 4 (1996): 369, 373; Bruno Latour, Reassembling the Social (Oxford: Oxford 
University Press, 2005), 54; Jennifer Daryl Slack and J. Macgregor Wise, Culture and Technology (New York: Peter Lang, 2007), 113; Jane Bennett, Vibrant Matter: A Political Ecology of Things (Durham, NC: Duke University Press, 2010), 23-24.

${ }^{6}$ See Joeri Bruyninckx on a tension between sound recording as a cultural practice and a scientific technique: Joeri Bruyninckx, Listening in the Field (Cambridge, MA: MIT Press, 2018), 6.

${ }^{7}$ John Durham Peters, The Marvelous Clouds (Chicago: University of Chicago Press, 2015), $176-77$.

${ }^{8}$ See, for example, Douglas Kahn, Earth Sound Earth Signal (Berkeley: University of California Press, 2013); Nicole Starosielski, The Undersea Network (Durham: Duke University Press, 2015); Jussi Parikka, A Geology of Media (Minneapolis: University of Minnesota, 2015); Lisa Parks and Nicole Starosielski, eds., Signal Traffic (Urbana: University of Illinois Press, 2015); Shannon Mattern, Code and Clay, Data and Dirt (Minneapolis: University of Minnesota Press, 2017); Nadia Bozak, The Cinematic Footprint (New Brunswick, NJ: Rutgers University Press, 2012); Richard Maxwell and Toby Miller, Greening the Media (Oxford: Oxford University Press, 2012); Stephen Rust, Salma Monani, and Sean Cubitt, eds., Ecomedia: Key Issues (London: Routledge, 2016); Hunter Vaughn, Hollywood's Dirtiest Secret (New York: Columbia University Press, 2019); James Leo Cahill, Zoological Surrealism (Minneapolis: University of Minnesota, 2019).

${ }^{9}$ Anna Tsing, Heather Swanson, Elaine Gan, Nils Burbandt, eds., Arts of Living on a Damaged Planet (Minneapolis: University of Minnesota Press, 2017), M7.

${ }^{10}$ Thom Van Dooren, Flight Ways (New York: Columbia University Press, 2014), 22, see also $4-5,8-9$. 
${ }^{11}$ Thom Van Dooren, Flight Ways (New York: Columbia University Press, 2014), 32.

${ }^{12}$ Alexandra Hui, "Imagining Ecologies through Sound: An Historic-Ecological Approach to the Soundscape of the Mississippi Flyway," MUSICultures 45, nos. 1-2 (2018): 37. Hui defines imagined ecologies as a community's understanding of themselves as part of a "multi-species ecological commons."

${ }^{13}$ Mimi Sheller and John Urry, "The New Mobilities Paradigm," Environment and Planning A 38 (2006): 210-11.

${ }^{14}$ Paul Kerlinger, How Birds Migrate, 2nd ed. (Mechanicsburg, PA: Stackpole Books, 2009), 60, 63.

15 "Mobility" in this work is understood to encompass "the large-scale movements of people, objects, capital and information across the world, as well as the more local processes of daily transportation, movement through public space and the travel of material things within everyday life.” Kevin Hannam, Mimi Sheller, and John Urry, "Editorial: Mobilities, Immobilities and Moorings, Mobilities," Mobilities 1, no. 1 (2006): 1. See also Tim Cresswell, "Mobilities I: Catching Up," Progress in Human Geography 35, no. 4 (2010); Mimi Sheller and John Urry, “The New Mobilities Paradigm,” Environment and Planning A 38 (2006); Peter Adey, Aerial Life (Oxford: Wiley-Blackwell, 2010).

${ }^{16}$ Mimi Sheller and John Urry, “The New Mobilities Paradigm," Environment and Planning A 38 (2006): 210-11.

${ }^{17}$ Nicole Starosielski, The Undersea Network (Durham: Duke University Press, 2015), 15. See also Brian Larkin, Signal and Noise (Durham, NC: Duke University Press, 2008), Nikhil Gupta Anand and Hannah Akhil Appel, eds., The Promise of Infrastructure (Durham, NC: Duke University Press, 2018). 
${ }^{18}$ Lisa Parks, "Earth Observation and Signal Territories: US Broadcast Infrastructure, Historical Network Maps, Google Earth, and Fieldwork," in Ecomedia: Key Issues, ed. Stephen Rust, Salma Monani, and Sean Cubitt (London: Routledge, 2016), 152. Parks writes that infrastructure sites are not only made of "metals, plastics, rubber, and electromagnetic fields, but also of soil, rock, vegetation, insects, lizards, birds, and animals, organic materials and life forms" (154-55). ${ }^{19}$ Jussi Parikka, A Geology of Media (Minneapolis: University of Minnesota, 2015), 4.

${ }^{20}$ Mimi Sheller, Aluminum Dreams: The Making of Light Modernity (Cambridge, MA: MIT Press, 2014), 10. The "aerospheric imagination" of aluminum is visualized on the cover of a book published by the Aluminum Company of America entitled Aluminum for Radio (1919): we see the Greek god Mercury riding a metallic steed through an art deco skyscape of clouds and radio towers.

${ }^{21}$ Mimi Sheller, Aluminum Dreams: The Making of Light Modernity (Cambridge, MA: MIT Press, 2014), 18-19. On World War II and aluminum, also see Sarah Nichols, "Aluminum by Design: Jewelry to Jets," in Aluminum by Design, ed. Sarah Nichols (Pittsburgh: Carnegie Museum of Art, 2000), 44.

${ }^{22}$ See Allison Carruth, "The Digital Cloud and the Micropolitics of Energy," Public Culture 26, no. 2 (2014): 350. See also Tung-hui Hu, A Prehistory of the Cloud (Cambridge, MA: MIT Press, 2015); Shannon Mattern, Code and Clay, Data and Dirt (Minneapolis: University of Minnesota Press, 2017); Jennifer Holt and Patrick Vonderau, "Where the Internet Lives," in Signal Traffic edited by Lisa Parks and Nicole Starosielski (Champaign: University of Illinois Press, 2015); Jennifer Gabrys, Digital Rubbish: A Natural History of Electronics (Ann Arbor: University of Michigan Press, 2011). On Hollywood cinema, see Nadia Bozak, The Cinematic 
Footprint (New Brunswick: Rutgers University Press, 2012), and Hunter Vaughan, Hollywood's Dirtiest Secret (New York: Columbia University Press, 2019).

${ }^{23}$ BirdLife International, State of the World's Birds: Taking the Pulse of the Planet (Cambridge, UK: BirdLife International, 2018); see also the 2019 report by the Intergovernmental SciencePolicy Platform on Biodiversity and Ecosystem Services (IPBES), https://www.ipbes.net/news/biodiversity-decline-land-degradation-puts-migratory-birds-risk and https://www.ipbes.net/news/Media-Release-Global-Assessment

${ }^{24}$ Kenneth V. Rosenberg, Adriaan M. Dokter, Peter J. Blancher, John R. Sauer, Adam C. Smith, Paul A. Smith, Jessica C. Stanton, Arvind Panjabi, Laura Helft, Michael Parr, and Peter P. Marra. et al., "Decline of the North American Avifauna," Science 366 (October 2019): 120-24.

${ }^{25}$ I am paraphrasing Thom Van Dooren, Flight Ways (New York: Columbia University Press, 2014), 83.

${ }^{26}$ John Faaborg, Saving Migrant Birds (Austin: University of Texas Press, 2002), 4-5.

${ }^{27}$ Brian L. Sullivan, Christopher L. Wood, Marshall J. Iliff, Rick E. Bonney, Daniel Fink, Steve Kelling. "eBird: A citizen-based bird observation network in the biological sciences," Biological Conservation, Vol. 142, 2009, p. 2282.

${ }^{28}$ John Burroughs, The Birds of John Burroughs (Woodstock, NY: Overlook Press, 1988), 61, 130, 144, 150. Similarly, Ralph Waldo Emerson's poem “May-Day” (1867) contains the lines, “I know the pretty almanac / Of the punctual coming-back, / On their due days, of the birds." Sparks, et al. "Birds," in Phenology: An Integrative Environmental Science, ed. M. D. Schwartz (Berlin: Springer Science, 2013). See John Durham Peters, The Marvelous Clouds (Chicago: University of Chicago Press, 2015), 176-77. 
${ }^{29}$ ESC can be found here: https://doi.org/10.3998/mpub.10120795. See also the special issue of the journal InTransition dedicated to the topic, http://mediacommons.org/intransition/intransition-audiographic-6-2019

${ }^{30}$ Jamie Lorimer, Wildlife in the Anthropocene (Minneapolis: University of Minnesota Press, 2015), 38-39.

${ }^{31}$ George Lakoff, "Why It Matters How We Frame the Environment," Environmental Communication 4, no. 1 (2010). Lakoff writes, "don't just give numbers and material facts. ... Tell stories that exemplify your values and rouse emotions," Also see Anja Kollmuss and Julian Agyeman, "Mind the Gap: Why Do People Act Environmentally and What Are the Barriers to Pro-Environmental Behavior?," Environmental Education Research 8, no. 3 (2002).

${ }^{32}$ I consider this kind of listening to be as an act of strategic or critical anthropomorphism. On anthropomorphism, see Jane Bennett, Vibrant Matter (Durham, NC: Duke University Press, 2010), 99. Also James Leo Cahill, Zoological Surrealism (Minneapolis: University of Minnesota Press, 2019), 97-98. Cahill writes that anthropomorphism "holds the possibility of sustaining an ethically charged translation and communication between different ontological positions that challenge ideologies of human exceptionalism," 97. Also see Lorraine Daston and Greg Mitman, eds., Thinking with Animals (New York: Columbia University Press, 2005); Erica Fudge, Animal (London: Reaktion, 2002); and Greg Garrard, Ecocriticism. (London: Routledge, 2011), 152-70. On music and birds, see Rachel Mundy, Animal Musicalities (Middletown, CT: Wesleyan University Press, 2018), 24.

${ }^{33}$ Velimer Khlebnikov, "The Radio of the Future" (1921), in Collected Works of Velimir Khlebnikov, Volume 1, ed. Charlotte Douglas (Cambridge, MA: Harvard University Press, 1987), 392. The term "lightning bird" is also associated with the folklore of several South African 
tribes. See Robert Godfrey, Bird-Lore of the Eastern Cape Province (Johannesburg:

Witwatersrand University Press, 1941); Lyall Watson, Lightning Bird (New York: Dutton, 1982); and Adrian Koopman, "Lightning Birds and Thunder Trees," Natalia 41 (2011): 40-60.

${ }^{34}$ I refer here to Ursula K. Le Guin, "The Carrier Bag Theory of Fiction," in The Ecocriticism Reader, ed. Cheryll Glotfelty and Harold Fromm, 355 (Athens: University of Georgia Press, 1996).

${ }^{35}$ Ursula Heise, Imagining Extinction (Chicago: University of Chicago Press, 2016), 5.

${ }^{36}$ Scott Weidensaul, Living on the Wind: Across the Hemisphere with Migratory Birds (New York: North Point Press, 1999), 38

${ }^{37}$ Susan Douglas, Listening In (Minneapolis: University of Minnesota Press, 2004), 34, 57-59.

${ }^{38}$ Raymond Williams, Television (New York: Routledge Classics, 2003), 19-20. See Lynn Spigel, Welcome to the Dreamhouse (Durham, NC: Duke University Press, 2001), 71-72.

${ }^{39}$ At times, the language used by the press to describe bird banding echoed that used for radio: one article talked about "a chain of bird banding stations" extending "from coast to coast." Walter E. Burton, “Whispering Wires Catch Birds' Strange Secrets," Popular Science, June 1931, 22.

40 "Large Aluminum Orders Are Placed for the Army," Wall Street Journal, June 30, 1917, 2. Matthew Evenden, "Aluminum, Commodity Chains, and the Environmental History of the Second World War," Environmental History 16 (January 2011): 71-72.

${ }^{41}$ Linda McKinney, "Singing Kites of Cambodia," in Art of the Refugee Experience, ed. Jan Rindfleisch (Cupertino, CA: De Anza College, 1988), 55; Mitchell Clark, “Aeolian-Bow Kites in China," Experimental Musical Instruments (March 1999): 41 Also see Nora Chadwick, “The Kite: A Study in Polynesian Tradition," Journal of the Royal Anthropological Institute of Great 
Britain and Ireland 61 (July-December 1931). Also see Hongxun Wang, Chinese Kites (Beijing: Foreign Language Press, 1989); Mitchell Clark, “Chinese Instruments in the Galpin Collection of the Museum of Fine Arts, Boston, with a Focus on the Sound-Makers," Galpin Society Journal 59 (May 2006): 213.

${ }^{42}$ See, for example, Christiaan Both, Chris A. M. Van Turnhout, Rob G. Bijlsma, Henk Siepel, Arco J. Van Strien, and Ruud P. B. Foppen, “Avian Population Consequences of Climate Change Are Most Severe for Long-Distance Migrants in Seasonal Habitats," Proceedings of the Royal Society B 277 (2010): 1259. Marcel E. Visser and Christiaan Both, "Shifts in Phenology Due to Global Climate Change: The Need for a Yardstick," Proceedings of the Royal Society B 272 (2005): 2561; Oscar Gordo, "Why Are Bird Migration Dates Shifting? A Review of Weather and Climate Effects on Avian Migratory Phenology," Climate Research 35 (December 2007): 37.

43 John Durham Peters, The Marvelous Clouds (Chicago: University of Chicago Press, 2015), $233,239$.

${ }^{44}$ Michael Brian Schiffer, "The Electric Lighthouse in the Nineteenth Century," Technology and Culture 46, no. 2 (April 2005): 277-78; John Naish, Seamarks: Their History and Development (London: Stanford Maritime, 1985), 118-20, 133.

45 Tower music is a genre of wind music "in seventeenth century Germany meant to be played from the towers of churches and municipal buildings"; see William R. Lee, "Wind Music of the Baroque," Journal of Band Research 20, no. 1 (Fall 1984), 2; Timothy A. Collins, "Of the Differences between Trumpeters and City Tower Musicians: The Relationship of Stadtpfeifer and Kammeradschaft Trumpeters," Galpin Society Journal 53 (April 2000): 51-59. 
${ }^{46}$ Lisa Parks, "Earth Observation and Signal Territories: US Broadcast Infrastructure, Historical Network Maps, Google Earth, and Fieldwork," in Ecomedia: Key Issues, ed. Stephen Rust, Salma Monani, and Sean Cubitt (London: Routledge, 2016), 141.

${ }^{47}$ Lisa Parks, "Earth Observation and Signal Territories: US Broadcast Infrastructure, Historical Network Maps, Google Earth, and Fieldwork," in Ecomedia: Key Issues, ed. by Stephen Rust, Salma Monani, and Sean Cubitt (London: Routledge, 2016), 152, 154-55.

${ }^{48}$ Mimi Sheller, Aluminum Dreams: The Making of Light Modernity (Cambridge, MA: MIT Press, 2014), 105-7. On Radio City Music Hall's aluminum foil as wallpaper, Sarah Nichols, "Aluminum by Design: Jewelry to Jets," in Aluminum by Design, ed. Sarah Nichols (Pittsburgh: Carnegie Museum of Art, 2000), 41.

${ }^{49}$ See "Uniform Antenna Marks Are Sought by the FCC in Revised Regulations," Broadcasting, September 1, 1937, 68. See also "Attire of Orange and White Ordered for Radio Antennae," Washington Post, September 14, 1937, 11.

${ }^{50}$ FCC advisory on lighting:

https://www.faa.gov/regulations_policies/advisory_circulars/index.cfm/go/document.information /documentID/1030047

${ }^{51}$ Judd A. Case, "Logistical Media: Fragments from Radar's Prehistory," Canadian Journal of Communication 38 (2013): 380-81.

${ }^{52}$ Paul Kerlinger, How Birds Migrate, 2nd ed. (Mechanicsburg, PA: Stackpole Books, 2009), 23. See also Eric Eastwood, Radar Ornithology (London: Methuen and Co., 1967), 61. ${ }^{53}$ Eric Eastwood, Radar Ornithology (London: Methuen and Co., 1967), 71-3; E. Eastwood, "Radar, Birds and Aircraft," Electronics \& Power, April 1969, 118; Donald R. Griffin, “The 
Physiology and Geophysics of Bird Navigation," Quarterly Review of Biology 44, no. 3

(September 1969): 256.

${ }^{54}$ See Roswitha Wiltschko and Wolfgang Wiltschko, Magnetic Orientation in Animals (Berlin: Springer, 1995), 44-45; Eric Eastwood, Radar Ornithology (London: Methuen and Co., 1967), $248-49$.

${ }^{55}$ Scott Weidensaul, Living on the Wind: Across the Hemisphere with Migratory Birds (New York: North Point Press, 1999), 62-63.

${ }^{56}$ Sidney A. Gauthreaux, "The Use of Weather Radar to Monitor Long-term Patterns of TransGulf Migration in Spring," in Ecology and Conservation of Neotropical Migrant Landbirds, ed. J. M. Hagan III and D. W. Johnston, 96-100 (Washington, D.C.: Smithsonian Institution Press, 1992),. David S. Wilcove, No Way Home: The Decline of the World's Great Animal Migrations (Washington, DC: Island Press), 2008, 22. On radar evidence, John Faaborg, Saving Migrant Birds (Austin: University of Texas Press, 2002), 30-4; Anthony D. Fox and Patrick D. Beasley, "David Lack and the Birth of Radar Ornithology," Archives of Natural History 37, no. 2 (2010): 330.

${ }^{57}$ https://www.partnersinflight.org/about/; Scott Weidensaul, Living on the Wind: Across the Hemisphere with Migratory Birds (New York: North Point Press, 1999), 341-42.;Paul Kerlinger, How Birds Migrate, 2nd ed. (Mechanicsburg, PA: Stackpole Books, 2009), 60; Scott K.

Robinson, "The Case of the Missing Songbirds," Consequences 3, no. 1 (1997).

${ }^{58}$ Bill Evans, interview, August 14, 2018. T. Edward Nickens, "Listening to Migrating Birds at Night May Help Ensure Their Safety,” Audubon, September-October 2013, http://www.audubon.org/magazine/september-october-2013/listening-migrating-birds-night-may; Andrew Farnsworth, "Flight Calls and Their Value for Future Ornithological Studies and 
Conservation Research,” The Auk 122, no. 3 (July 2005): 735; O. G. Libby, "The Nocturnal Flight of Migrating Birds," The Auk 16, no. 2 (April 1899): 140.

${ }^{59}$ Joeri Bruyninckx, Listening in the Field (Cambridge, MA: MIT Press, 2018), 4.

${ }^{60}$ See Joeri Bruyninckx, Listening in the Field (Cambridge, MA: MIT Press, 2018), and Randolph Scott Little, For the Birds (Self-published manuscript, 2003), 33-34.

${ }^{61} \mathrm{http}: / /$ oldbird.org/mic/21c-setup.htm; T. Edward Nickens, "Listening to Migrating Birds at Night May Help Ensure Their Safety," Audubon, September-October 2013, http://www.audubon.org/magazine/september-october-2013/listening-migrating-birds-night-may ${ }^{62}$ See Liesbeth Koot and Menno Grootveld, "Interview with Jon Hagstrum on Migrating Birds," Sonic Acts Research Series \#11, http://sonicacts.com/portal/research-series/interview-with-jonhagstrum-on-migrating-birds; Jonathan Hagstrum, "Infrasound and the Avian Navigational Map," Journal of Experimental Biology 203 (2000): 1106. On infrasound, see also Scott Weidensaul, Living on the Wind: Across the Hemisphere with Migratory Birds (New York: North Point Press, 1999), 64; Alfred J. Bedard and Thomas M. Georges, “Atmospheric Infrasound," Physics Today 53 (March 2000): 33-34.

${ }^{63}$ Ernest Braun and Stuart MacDonald, Revolution in Miniature (Cambridge: Cambridge University Press, 1978), 17, 29.

${ }^{64}$ Michael Brian Schiffer, The Portable Radio in American Life (Tucson: University of Arizona Press, 1991), 173-76. Ernest Braun and Stuart MacDonald, Revolution in Miniature (Cambridge: Cambridge University Press, 1978), 38.

${ }^{65}$ Etienne Benson, Wired Wilderness (Baltimore: Johns Hopkins University Press, 2010), 5.

${ }^{66}$ Lynn Spigel, Welcome to the Dreamhouse (Durham, NC: Duke University Press, 2001), 71. 
${ }^{67}$ Emily A. McKinnon and Oliver P. Love, "Ten Years Tracking the Migrations of Small Landbirds: Lessons Learned in the Golden Age of Bio-logging," The Auk 135, no. 4 (2018): 835. C. Francis, et al., BOU Proceedings—Birds in Time and Space: Avian Tracking and Remote Sensing (2016), http://www.bou.org.uk/bouproc-net/tracking/poster-francis-etal.pdf, 1. For a recent statement about the future of wildlife telemetry and an "internet of wings," see Jane C. Hu, “An Internet of Wings,” Anthropocene, July 2017, https://anthropocenemagazine.org/2017/08/an-internet-of-wings/

${ }^{68}$ Hugo Reinert, "The Care of Migrants: Telemetry and the Fragile Wild," Environmental Humanities 3 (2013): 4; Charles Bergman, "Inventing a Beast with No Body: Radio-Telemetry, the Marginalization of Animals, and the Simulation of Ecology," Worldviews 9, no. 2 (2005): 257, 266.

${ }^{69}$ Alexander Pschera, Animal Internet: Nature and the Digital Revolution (New York: New Vessel Press, 2016), 99-100, 139.

${ }^{70}$ Alexander Pschera, Animal Internet: Nature and the Digital Revolution (New York: New Vessel Press, 2016), 11, 13, 14, 161-62.

${ }^{71}$ In Antoine Bertin's "12 Hours in the Life of a Fox," the artist attached a recording collar to a fox and followed his movements via a GPS in his collar. The recorder was made to automatically drop off after twelve hours. See https://soundcloud.com/antoine-bertin/12-hours-in-the-life-of-afox; and http://www.antoinebertin.org/12-hours-in-the-life-of-a-fox/

${ }^{72}$ Anna Lowenhaupt Tsing, The Mushroom at the End of the World (Princeton: Princeton University Press, 2015); Donna J. Haraway, Staying with the Trouble (Durham, NC: Duke University Press, 2016).

${ }^{73}$ Ursula Heise, Imagining Extinction (Chicago: University of Chicago Press, 2016), 12-13. 
${ }^{74}$ Heise, Imagining Extinction, 12-13.

${ }^{75}$ On the snow goose population, see K. F. Abraham, R. L. Jefferies, and R. T. Alisauskas, "The Dynamics of Landscape Change and Snow Geese in Mid-Continent North America," Global Change Biology 11 (2005): 841-55; G. Gauthier, J.-F. Giroux, A. Reed, A. Bechet, and L. Belanger, "Interactions between Land Use, Habitat Use, and Population Increase in Greater Snow Geese: What Are the Consequences for Natural Wetlands?," Global Change Biology 11 (2005): 856-68; David N. Koons, Lisa M. Aubry, and Robert F. Rockwell, "Liberalized Harvest Regulations Have Not Affected Overabundant Snow Geese in Northern Manitoba," The Condor: Ornithological Applications 121, no. 2 (2019): 1-13; J. Lefebvre, G. Gauthier, J. F. Giroux, A. Reed, E. T. Reed, and L. Bélanger, "The Greater Snow Goose Anser caerulescens atlanticus: Managing an Overabundant Population," Ambio 46, Suppl 2 (2017): 262-74. 